\title{
Kinetics Etude of the Experimental Leaching of Sphalerite Using Acidic Lixiviant
}

\author{
Elbar D* and Barkat D \\ Laboratory of Chemical Molecular and Environnement, University of Biskra, Algeria \\ *Corresponding author: Elbar D, Laboratory of Chemical Molecular and Environnement, University of Biskra 07000, Algeria
}

Submission: 眥 February 01, 2018; Published: 鮆 March 22, 2018

\begin{abstract}
The influence of physico-chemical parameters such as acid concentration, temperature, particle size and time of leaching on the chemical dissolution of the sphalerite ore in sulfuric acid was examined. At a temperature of $358 \mathrm{~K}$ by 2 mol.l-1 H2SO4, a stirring speed of $300 \mathrm{rpm}$, initial solid / liquid ratio of $10 \mathrm{~g} / \mathrm{L}$ and particle size $(-125+63 \mu \mathrm{m})$, about $99 \%$ of zinc was extracted inside $120 \mathrm{~min}$. The experimental data of this leaching technique was established by way of the shrinking core model under chemically reaction controlled processes, the corresponding activation energy for the recovery of zinc Ea calculated from the Arrhenius expression to be $18.63 \mathrm{~kJ} / \mathrm{mole}$.
\end{abstract}

Keyword: Sphalerite ore; Leaching; Sulfuric acid; Dissolution kinetics

\section{Introduction}

Algeria is rich in minerals, the country has many iron, lead, zinc, copper, calamine, antimony and mercury mines. The most productive are those of iron and zinc. At the Chaabet el Hamra, leadzinc deposit, there are some 5Mt of reserves averaging 5\% metal content. Sphalerite is a mineral that is the chief ore of zinc. Exists in form of a clear crystal, it can simply be separated from gangue. Sphalerite also known as Blende or Zinc Blende; Which is generally coupled by means of sulphide minerals, such as pyrite (FeS2), covellite $(\mathrm{CuS})$, chalcopyrite $(\mathrm{CuFeS} 2)$, and galena $(\mathrm{PbS})$.

The direct leaching of the sphalerite was establish a significant attention in recent years because this processes is economical and more environmental suitable [1], it use diverse leaching agents as well as sulfuric acid, ammonia, hydrochloric acid, and cyanide was developed by Nesbitt and Xue, However, in industrial scale the sulfuric acid is the best successful leaching agent [2]. The direct leaching of zinc from a sphalerite concentrate with oxygen as an oxidant in sulfuric acid solutions was examine by Yan et al. [3]. A study was achieved to evaluate the influence of different factors such as particle size, reaction time, and temperature on zinc dissolution. A lot of authors supported the shrinking core model in sulphides ores leaching [4-8]. The study kinetics of leaching is very significant to understand the dissolution process of metals, relatively several studies have been done for leaching kinetics of metal sulfide which controlled by chemical reaction [9].
This paper presents experiment a chemical leaching of sphalerite in sulfuric acid medium, to establish the most constructive parameters such as acid concentration, leaching time, particle size and temperature to this process for the recovery of zinc. The mechanism of the dissolution reaction was discovered.

\section{Experimental}

\section{Materials}

The feed for this study was sphalerite concentrate from Cheabet Elhamra mine, Algeria. Table 1 shows the chemical compositions of the feed. Figure 1 demonstrates the XRD pattern of the sphalerite concentrate.

Table 1: Chemical composition of hydrometallurgical residue (mass fraction, \%).

\begin{tabular}{|c|c|c|c|c|}
\hline Elements & $\mathrm{Zn}$ & $\mathrm{S}$ & $\mathrm{Fe}$ & $\mathrm{Cu}$ \\
\hline Content & 41.61 & 39.38 & 13.71 & 0.14 \\
\hline
\end{tabular}

Leaching procedure: Leaching tests were carried out in a flask placed on a thermostatically controlled magnetic stirrer. The solution temperature was controlled to specific values with continuously monitored by a thermometer. Samples of clay weighing $10 \mathrm{gm}$ were taken in $100 \mathrm{ml}$ of leaching solution. The optimum concentrations of the acids were determined by dissolution in $\left(0.25,0.5,1\right.$ and $\left.2 \mathrm{mol.l}^{-1}\right)$ sulfuric acid solutions. 
The subsequent leaching was performed in the optimized acid concentrations at temperatures of $(298,318,338$ and $358 \mathrm{~K})$ for (30, 60, 90, and 120 minute) at each temperature. At the finish of leaching for a specific period of time at a specific temperature of leaching solution was taken out by a pipette. The collected sample of leach liquor was cooled; filtered and metal content was analyzed by atomic absorption spectrometry (AAS Shaker D407).

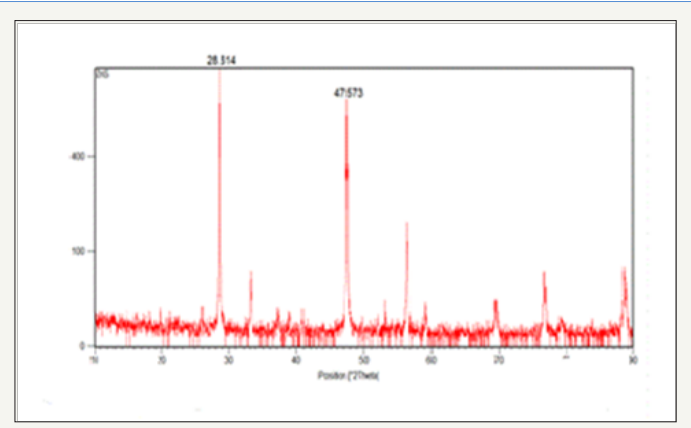

Figure 1: The XRD pattern of the zinc sulfide concentrate.

\section{Results and Discussion}

\section{Results of leaching}

Effect of acid concentration: Increasing the concentration of sulfuric acid 0.5 to 2 mol.l-1 significantly increased the rate of dissolution. It has irrefutably been shown that decreasing the $\mathrm{pH}(0.5$ to 1.5$)$ increases the rate of dissolution in sulfuric acid medium $[10,11]$. The experimental results obtained from Figure 2 showed that concentration of sulfuric acid had the maximum effect on the rate of zinc dissolution, after particle size, from 20 to 120 min of leaching. During the first 20 min of leaching, the effect of concentration of sulfuric acid was in third place, after temperature.

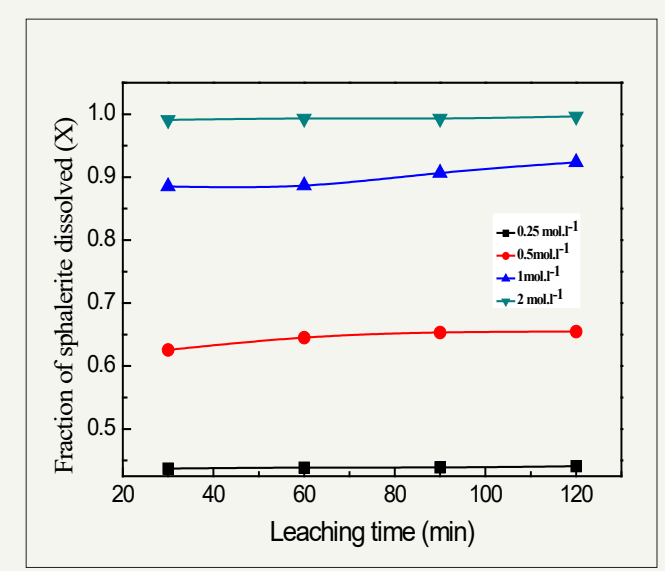

Figure 2: Effect of $\mathrm{H}_{2} \mathrm{SO}_{4}$ concentration on zinc dissolution at various leaching time. Experimental conditions: particle size = $-125+63 \mu \mathrm{m} ;$ temperature $=338 \mathrm{~K}$.

Effect of leaching time: Effect of leaching time on the recovery of zinc metal was studied in these experiments variables: constant sulfuric acid concentration (2mol.l-1), different particle size for solid-to-liquid ratio (1:10) and at temperature of leaching solution (358K). Figure 3 demonstrate that the solubility of zinc sulfide in acidic solution is enhanced by increasing leaching time; when the leaching time was over $90 \mathrm{~min}$, the curve of leaching rate was changed to be steady; the suitable leaching time is $120 \mathrm{~min}$. this agrees with results of GU Yan et al. [3].

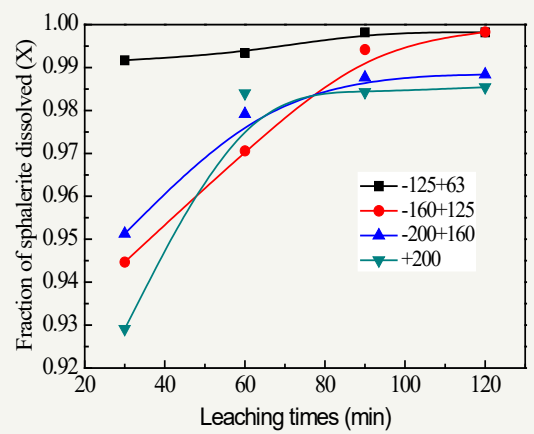

Figure 3: Fraction of zinc dissolved vs. leaching time at different particle size.

Effect of particle size: The effect of particle size on the extraction of zinc was examined using different size fractions. The results are summarized in Figure 4. It showed that the rate of leaching increased significantly with decreasing particle size and it had the maximum effect on the extraction of zinc at all times. Many studies have accounted the different effects of particle size in increasing the rate of recovery zinc from sphalerite ores $[12,13]$.

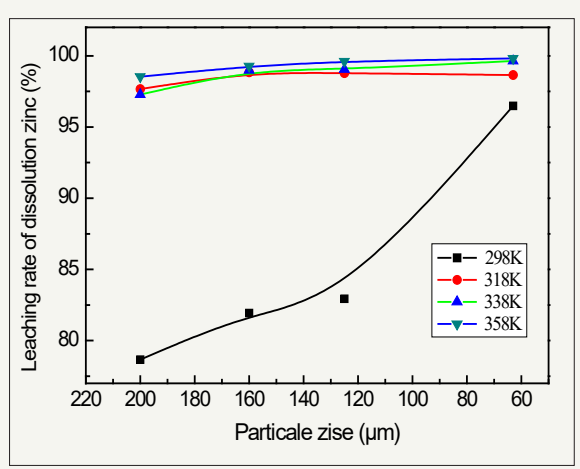

Figure 4: Effect of particle diameter on zinc dissolution at different temperature. Experimental conditions: 2 mol.1-1 $\mathrm{H}_{2} \mathrm{SO}_{4}$, $120 \mathrm{~min}$.

Effect of leaching temperature: Temperature has evident effect on leaching of zinc. In actuality temperature was the main effect on the rate of dissolution, after particle size, just before 20 min of contact time. It is evidently from Figure 5 that the solubility of zinc was enhanced with increasing temperature, at $298 \mathrm{k}$ about $82.9 \%$ of zinc was extracted, while the maximum extraction of $\mathrm{Zn}$ approach about $99.2 \%$ at optimum temperature of leaching solution $358 \mathrm{~K}$.

Average speed of leaching: Previous curves are parabolic. They have a large slope branch representative a rapid leaching stage in the first 30 minutes and a second branch of low slope (second slower phase). Figure 6 shows that the average speed between 0 
and 30 minutes are logically very high since they are mainly related to the dissolution of the oxides, in the time interval of 60 and 120 minutes, there is only sulfides which dissolve during this phase following the reaction:

$$
\mathrm{ZnS}+\mathrm{H}_{2} \mathrm{SO}_{4} \rightarrow \mathrm{ZnSO}_{4}+\mathrm{H}_{2} \mathrm{~S} \text {. }
$$

The average speed of zinc dissolution rate varies with temperature. At $25^{\circ} \mathrm{C}$ the sphalerite dissolves with a very low speed evaluated $103 \times 10-5 \mathrm{~g} / \mathrm{l} . \mathrm{min}$. This rate speed increases to $194 \times 10$ $5 \mathrm{~g} / \mathrm{l} . \mathrm{min}$ at $85^{\circ} \mathrm{C}$ as demonstrate the Figure 7.

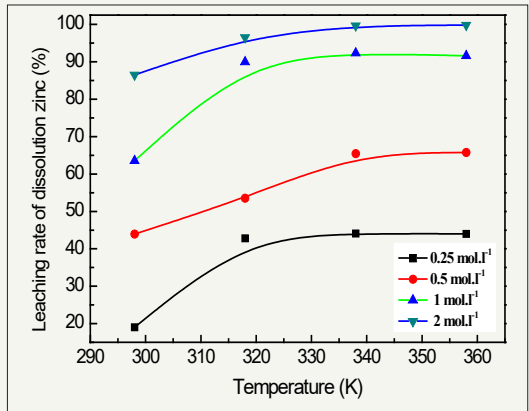

Figure 5: Effect of temperature on the recovery of zinc at different concentration.

Experimental conditions: leaching time $120 \mathrm{~min}$, particle size $=$ $-125+63 \mu \mathrm{m}$

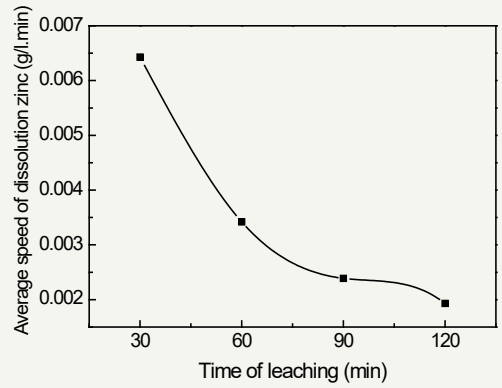

Figure 6: Effect of temperature on the recovery of zinc at different concentration.

Experimental conditions: leaching time $120 \mathrm{~min}$, particle size $=$ $-125+63 \mu \mathrm{m}$

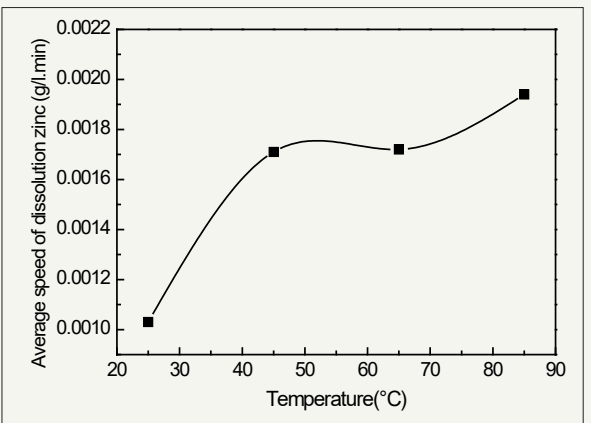

Figure 7: The average speed of dissolution zinc as a function of temperature.

Experimental conditions: time of leaching $120 \mathrm{~min}, 2 \mathrm{~mol} .1$ $1 \mathrm{H} 2 \mathrm{SO} 4$, particle size $=160+125 \mu \mathrm{m}$

\section{Discussion}

\section{Leaching kinetic model}

The rate of reaction in fluid-solid systems can be determined by a non-catalytic heterogeneous model which has a number of applications in chemical and hydrometallurgical processes. The shrinking core model is the most frequently used. The shrinking core model regard as that the leaching process is controlled either by the diffusion of reactant through the solution boundary layer, or through a solid product layer, or by rate of the surface chemical reaction [9]. The experimental data obtained at different temperatures in this study have been evaluated using surface chemical reaction control model (Eq. 2).

Chemical reaction controlled process:

$$
\begin{aligned}
& 1-X=(1-k t)^{3} \\
& 1-(1-X)^{\frac{1}{3}}=k t
\end{aligned}
$$

where 1-X: fraction not dissolved; $\mathrm{k}$ is the apparent rate constant.

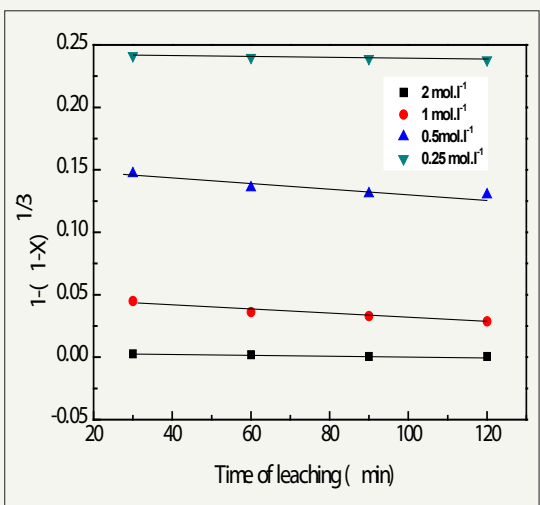

Figure 8: Plot of $1-(1-\mathrm{X})^{1 / 3}=\mathrm{kt}$ vs. leaching time at various $\mathrm{H}_{2} \mathrm{SO}_{4}$ concentrations.

Figure $8 \& 9$ confirm that there is a linearity between the term [1 - $(1-X) 1 / 3]$ and leaching time, we can therefore assume that the shrinking core model is reliable with the dissolution of zinc concentrate processed. The modeling equations are of type:

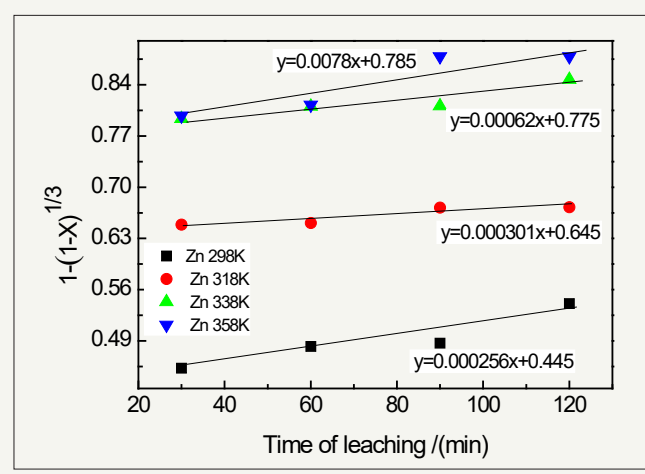

Figure 9: Plot of $1-(1-X) 1 / 3=k t$ vs. leaching time for zinc leaching at various temperatures by particle size $(-125+63 \mu \mathrm{m}), 2$ mol.1-1 $\mathrm{H} 2 \mathrm{SO} 4$ solution. 


$$
\mathrm{y}=\mathrm{ax}+\mathrm{b}
$$

where $\mathrm{b}$ is the rapid dissolution of the oxides in the first 20 minutes. This has the same estimation with the results of Kitobo [14].

\section{Evaluation of activation energy of dissolution Sphalerite}

We use the rate constants resultant $\mathrm{k}$ from the slope in Figure 8 , which $\mathrm{k}$ is exponentially dependent on temperature by the Arrhenius equation formulated as:

$$
k=A \exp \left(-\frac{E a}{R T}\right)
$$

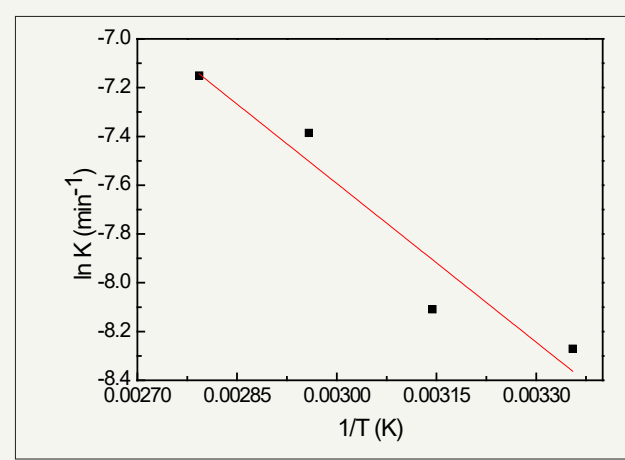

Figure 10: ln k vs.1/T (K-1): Arrhenius plot for determining activation energy, Ea, for sphalerite dissolution in 2 mol.l-1 $\mathrm{H} 2 \mathrm{SO} 4$.

where A (min-1) the Arrhenius constant, Ea (J/mol) is the activation energy, $\mathrm{T}$ the absolute temperature and $\mathrm{R}$ is the universal gas constant $(8.314 \mathrm{~J} / \mathrm{K} . \mathrm{mol})$. This law concurs to calculate the activation energy $\mathrm{Ea}$, which is the minimum that the reactants must acquire to be able to react and turn into a product of leaching reaction energy. The Arrhenius diagram in Figure 10 was drawn; the value of activation energy is calculated by multiplying the slope of Arrhenius curve by the value of universal gas constant. The calculated value $18.62 \mathrm{~kJ} / \mathrm{mol}$ and the Arrhenius constant $\mathrm{A}$ is $9.97 \times 10-4 \mathrm{~min}-1$. When the value of the activation energy is between 4.2 and $12.6 \mathrm{KJ} / \mathrm{mol}$, the reaction rate is controlled purely by the diffusion and when this value is greater than $18 \mathrm{KJ} / \mathrm{mol}$, the control is purely chemical kinetics [15].

\section{Conclusion}

On the foundation of consequences of this study, we conclude the subsequent results:

The fraction of sphalerite dissolved at a particular time increase by increasing the concentration of sulfuric acid and it is inversely proportional to the average diameter of the particles. The extraction rates from the residue after 120 min of treatment is $99.8 \%$ by the side of the optimum leaching conditions: solid-to-liquid ratio (1:10), temperature leaching 358K, sulfuric acid concentration 2 $\mathrm{mol} / \mathrm{L}$, and smaller particle size $(-125+63 \mu \mathrm{m})$.

The shrinking core model with chemical reaction controlled process was used to determine the kinetics dissolution of sphalerite in acidic medium and the activation energy was found to be 18.45 $\mathrm{kJ} /$ mole for this process.

\section{References}

1. M Deniz Turan, Soner Altundogan, Fikret Tqmen (2004) Recovery of zinc and lead from zinc plant residue. Hydrometallurgy 75:169-176.

2. H Nesbitt, S Xue (1995) Recycling of base metals from metal wastes of brass foundries. Treatment and Minimization of Heavy Metal-containing Wastes Conf., Las Vegas, USA, pp. 43-56.

3. Gu Y, Zhang TA, Liu Y, Mu WZ, Zhang WG, Dou XL, Jiang ZH (2010) Pressure acid leaching of zinc sulfide concentrate. Trans Nonferrous Met Soc China 20(1): s136-s140.

4. S Aydogan, A Aras, G Ucar, M Erdemoglu (2007) Dissolution kinetics of galena in acetic acid solutions with hydrogen peroxide. Hydrometallurgy 89(3-4): 189-195.

5. Hackl RP, Dreisinger DB, Peter E, King JA (1995) Passivation of chalcopyrite during oxidative leaching in sulfate media. Hydrometallurgy 39(13): $25-48$.

6. Markus H, Fugleberg S, Valtakari D, Salmi T, Murzin DY, et al. (2004) Kinetic modelling of a solid-liquid reaction: reduction of ferric iron to ferrous iron with zinc sulphide. Chemical Engineering Science 59(4): 919-930.

7. Majima H, Awakura Y, Mishima T (1985) The Leaching of Hematite in Acid Solutions. Metall Trans B 16(1): 23-30.

8. Hirato T, Majima H, Awakura Y (1987) Metall Trans B31: 158.

9. O. Levenspiel (1999) Chemical Reaction Engineering, ( $2^{\text {nd }}$ edn), John Wiley, New York, USA.

10. Souza AD, Pina PS, Silva CA, Leão VA (2009) Effect of iron in zinc silicate concentrate on leaching with sulphuric acid. Hydrometallurgy 95(3-4): 207-214.

11. Yang JL, Ma S, Liu P, Wang G, Su X, et al. (2001) Hydrometallurgical treatment of low grade zinc oxide ore. Advanced Materials Research 158: $140-144$.

12. Li CX, Xu H, Deng Z, Li X, Li M, et al. (2010) Pressure leaching of zinc silicate ore in sulfuric acid medium. Transactions of Nonferrous Metals Society of China 20(5): 918-923.

13. Xu H, Wei C, Li C, Fan G, Deng Z, Li M, Li X (2010) Sulfuric acid leaching of zinc silicate ore under pressure. Hydrometallurgy 105(1-2): 186-190.

14. W. Kitobo (2009) Remediation and recovery of sulphide mine discharges from Katanga: case of the tailings of the Old Kipushi Concentrator. Ph.D Thesis University Liege, Belgium, Europe.

15. Abdel AEA (2000) Kinetics of sulfuric acid leaching of low-grade zinc silicate ore. Hydrometallurgy 55(3): 247-254. 
Creative Commons Attribution 4.0 International License

For possible submissions Click Here

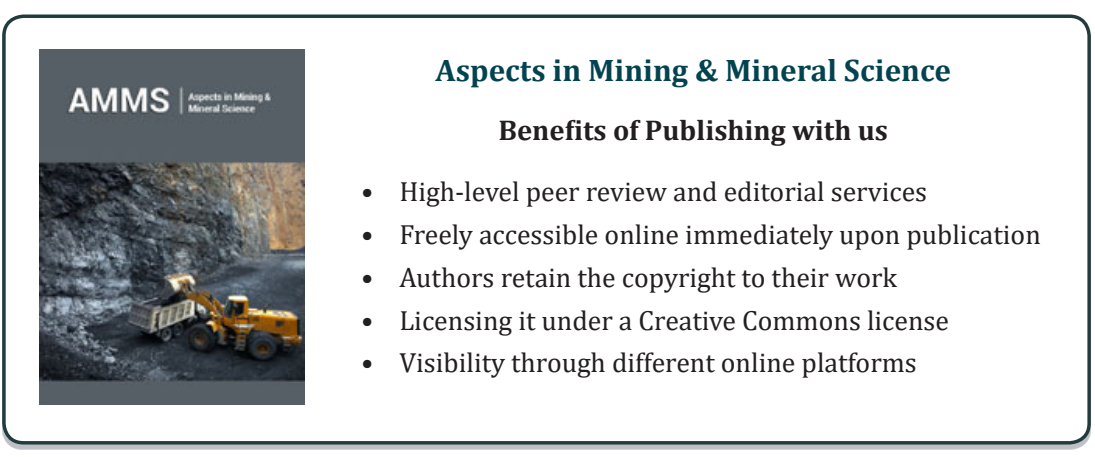

